\title{
Comminuted fracture of patella treated by primary Ilizarov external fixation: a case report
}

\author{
Godhasiri Ponugoti*, Harshad Mohanlal Shah, Sandeep Reddy, Namratha C. Kolsur
}

Department of Orthopaedics, Ramaiah Medical College, Bangalore, Karnataka, India

Received: 19 March 2020

Revised: 10 May 2020

Accepted: 12 May 2020

\author{
*Correspondence: \\ Dr. Godhasiri Ponugoti, \\ E-mail: drponugoti.godhasiri@gmail.com
}

Copyright: (c) the author(s), publisher and licensee Medip Academy. This is an open-access article distributed under the terms of the Creative Commons Attribution Non-Commercial License, which permits unrestricted non-commercial use, distribution, and reproduction in any medium, provided the original work is properly cited.

\begin{abstract}
Tension band wiring (TBW) is the conventional procedure for transverse patellar fractures. Comminuted fractures of patella are difficult to treat by TBW. Routine osteosynthesis procedures are prone for infection, implant failure and symptomatic hardware in such cases. We are reporting a case of comminuted patellar fracture in a 62 years old lady treated by Ilizarov external fixator. Patient presented with h/o fall and injury to right knee. There was swelling of the right knee. She was unable to bear weight and move her knee. Radiograph revealed a comminuted patellar fracture. Pre-operative evaluation was done. Ilizarov external fixation was done under spinal anaesthesia with one half ring and 5 trans osseous Ilizarov wires. The patient was allowed full weight bearing. Knee ROM was allowed. The fixator was removed after 4 months and physiotherapy continued. The patient was followed up for 3 years. She has full range of knee movements and is able to squat and sit cross-legged and the radiographs show good union. The Ilizarov external fixator in this case helped us to treat a comminuted fracture without opening of the fracture site and has prevented complications.
\end{abstract}

Keywords: Patella fracture, Comminuted fracture Patella, Ilizarov fixation of patella, External fixation for patella fractures

\section{INTRODUCTION}

Patella fractures account for approximately $1 \%$ of all skeletal injuries. ${ }^{1}$ Causes like extensor mechanism damage; stiffness of knee and articular surface incongruity pose challenges in treatment. ${ }^{2}$ Tension band wiring (TBW) remains the standard option of treatment with addition of cerclage wiring in comminuted fractures. These fractures are also fixed with interfragmentary screws or combinations of SS wires, $\mathrm{k}$ wires and screws. Fixation failure is common in patients with communited fractures, patients with osteoporotic bones and in elderly patients leading to non-union, loosening of implant and prominent hardware. Though conservative management, partial and total patellectomy are an option, they pose complications and extensor mechanism failure. ${ }^{3,4}$ Ilizarov external fixation is a successful method in treating comminuted patella fractures.

\section{CASE REPORT}

A 62 years old lady presented with history of fall and sustained injury to the right knee. She incurred a closed right patella fracture. The radiograph showed comminution of the fracture (Figure 1).

The patient was evaluated and taken up for surgery. The surgery was performed under spinal anaesthesia under tourniquet control. One half ring was used for five trans osseous Ilizarov wires. Four of these wires were transversely fixed. Three of these wires were fixed with tensioning of the wires to a threaded rod dropped from the 
ring on either side of the knee joint into slotted washers. One wire was fixed by bending it towards the slotted washers onto the threaded rod. The fifth wire was inserted obliquely and connected to posts to form a drop wire (Figure 2 and 3). This was checked by image intensifier on both AP and lateral views.

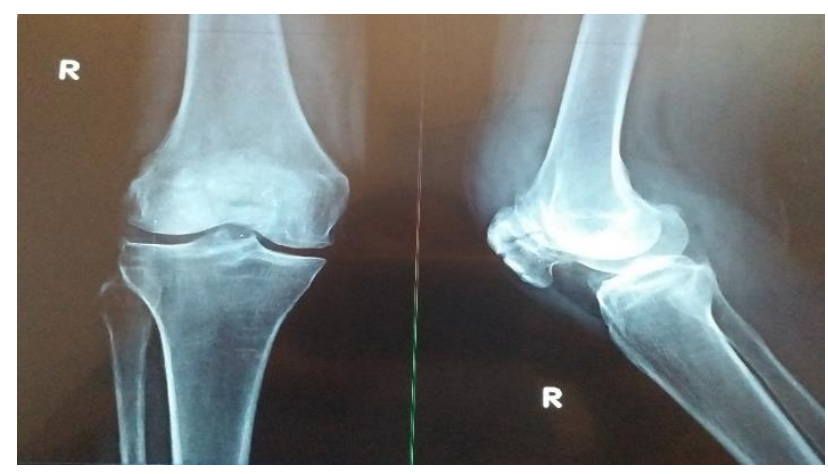

Figure 1: AP and lateral views showing comminuted fracture of patella.

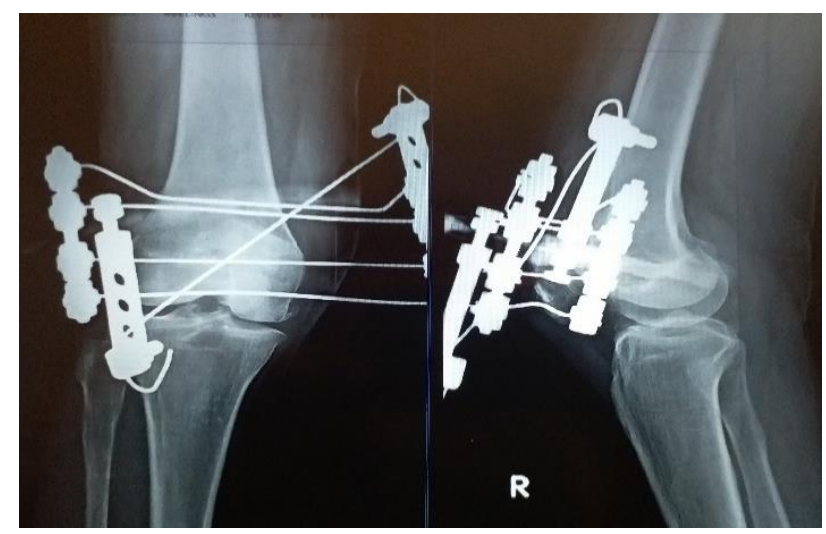

Figure 2: Post-operative radiograph with Ilizarov fixator.

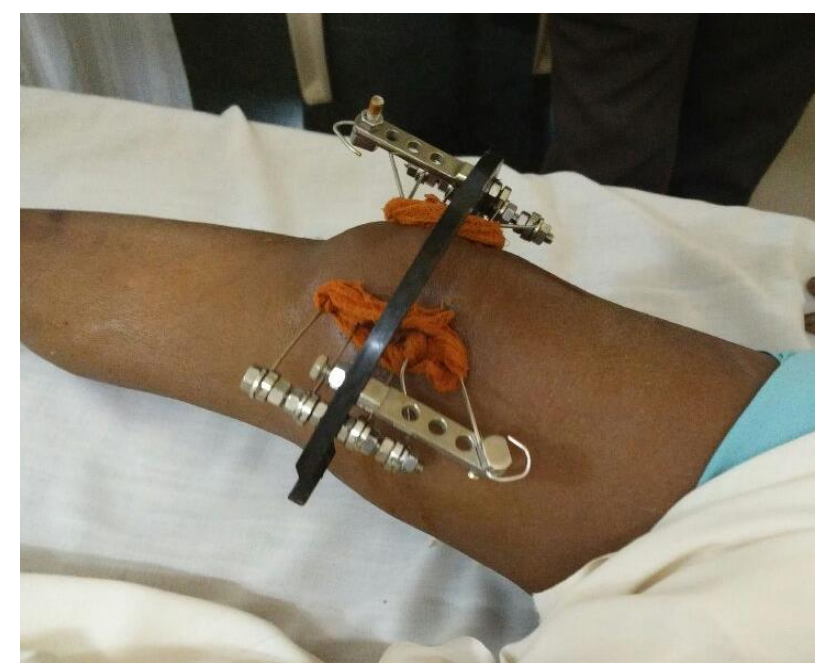

Figure 3: Clinical photograph with fixator.
The patient was allowed weight bearing the next day, knee ROM exercises started. After 4 months the fixator was removed and physiotherapy continued. Her knee ROM further improved and there was no extensor lag.

The patient was followed up every month for the $1^{\text {st }} 6$ months. The last follow up was after 3 years after fixator removal. She has normal knee movements. Her ADL are unhampered. She is able to sit cross-legged, squat and climb stairs with no difficulty and her radiographs show good union and consolidation (Figure 4 and 5). The added advantage is the minimal scarring (Figure 6).

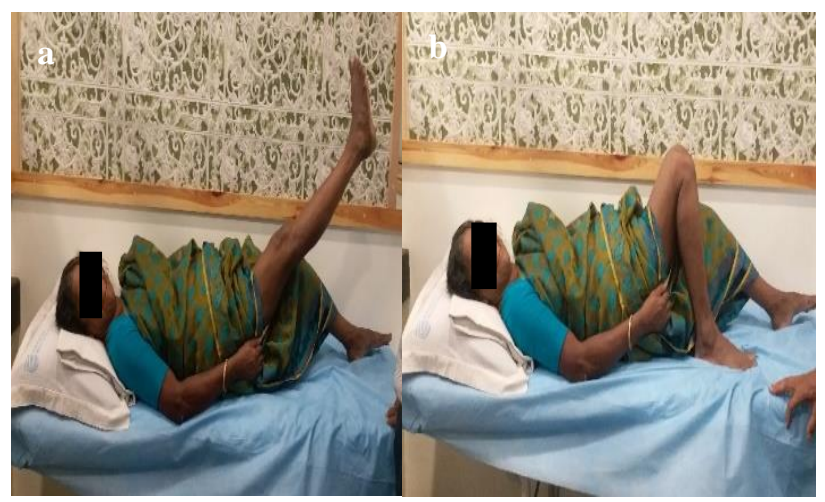

Figure 4 (a and b): Clinical photographs showing good ROM - 3 years follow up.

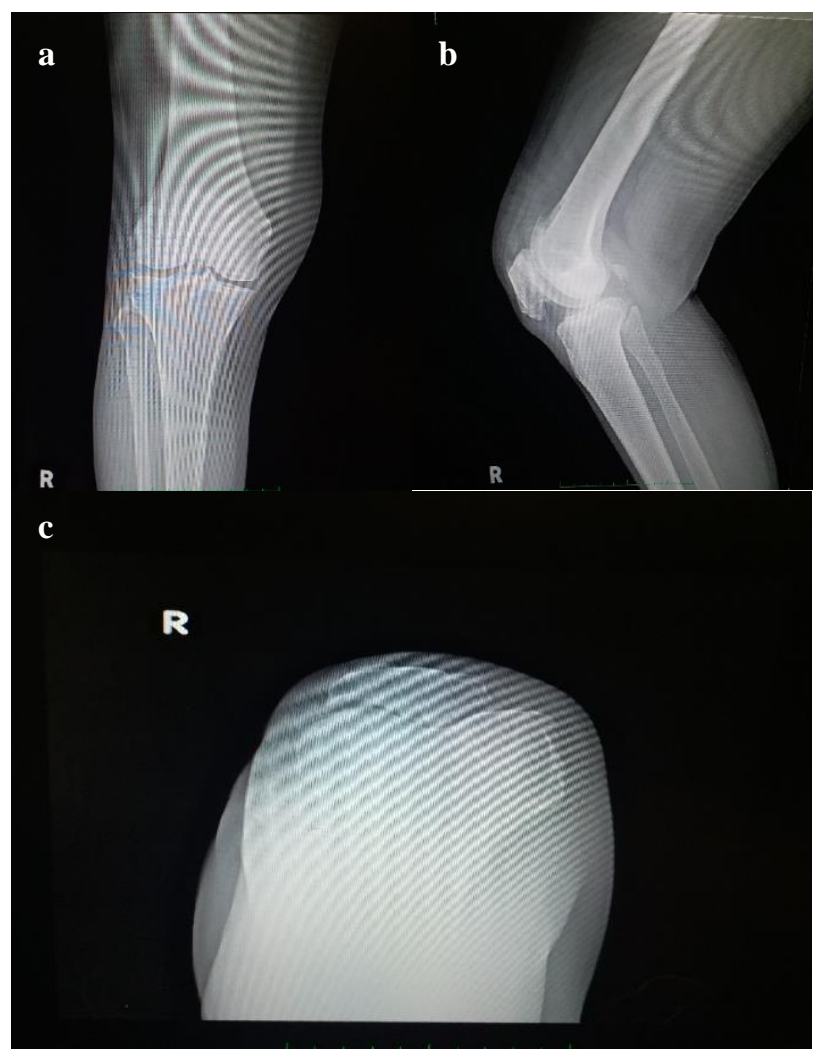

Figure 5 (a, b and c): AP, LAT and skyline views showing good union and consolidation -3 years postoperative. 


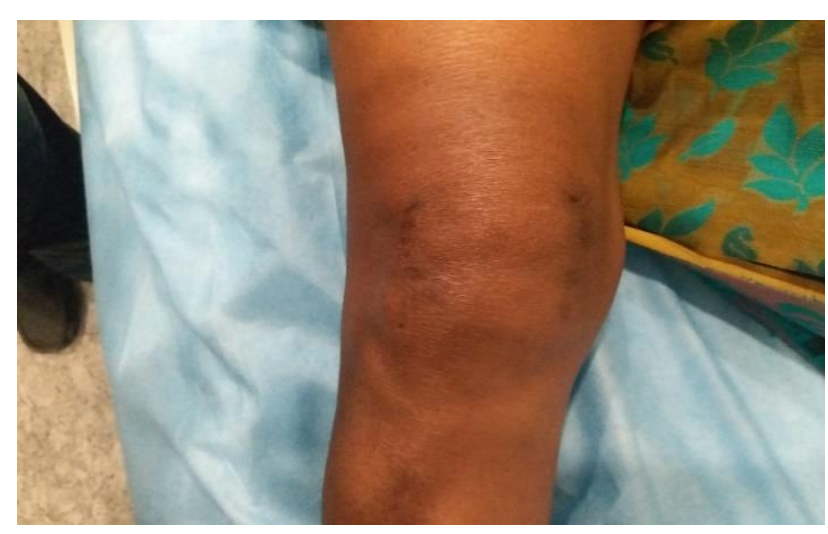

Figure 6: Minimal scarring.

\section{DISCUSSION}

Comminuted patellar fractures are common elderly patients and in patients with osteopenic bones. Prevention of implant failure, early mobilization and achievement of good knee range of movements are goals of treatment. Though locking plates or mesh augmentation are valid treatment options in comminuted fractures, they are more expensive and symptomatic implant problems are common with them. ${ }^{4}$

Studies by Kastelec and Veselko show that patients undergoing partial patellectomy in comminuted fractures did significantly worse in functional outcome scores, knee pain scores, and ROM. ${ }^{5}$ Studies by Hashino et al show that elderly patients treated by TBW had high chances of implant failure. ${ }^{6}$

Ilizarov had suggested treatment of fresh fracture of the patella by two wires and a plastic half ring ASAMI group suggested treatment of fresh fracture of the patella by two olive wires from opposite directions, each affixed to halfrings which were then interconnected. ${ }^{7,8}$ Baruah, reported a case of implant failure of patellar fracture treated successfully with Ilizarov external fixator. ${ }^{9}$

Studies done by Dr. Mohammad Ismail Wardak by using compression external fixation (CEF) device based on external tensioned wire construct. 84 cases were treated with this device all fractures attained union. Minor complications of wire irritation were seen in 14 patients and 1 patient had poor knee motion due to fibro ankylosis of the joint. ${ }^{10}$

Studies by Bari et al show 18 patients treated with external fixation with compressive external fixation device developed by Dr. Mohammad Ismail Wardak. Union was achieved in all the cases. Except 2 cases who had 90degree knee ROM, the remaining patients achieved good knee ROM. ${ }^{11}$

\section{CONCLUSION}

The Ilizarov external fixator is a versatile method of treating comminuted patellar fractures and osteoporotic patellar fractures. It offers the advantage of early weight bearing and knee ROM. It prevents complications of implant failure and symptomatic hardware and is successful in achieving solid union. It is a minimally invasive surgery without the need for sutures.

\section{Funding: No funding sources \\ Conflict of interest: None declared \\ Ethical approval: Not required}

\section{REFERENCES}

1. Bostrom A. Fracture of the patella. A study of 422 patellar fractures. Acta Orthop Scand Suppl. 1972;143:1-80.

2. Luo TD, Pilson H. Fracture, Patella. Treasure island, FL: Stat pearls; 2018.

3. Shabat S, Mann G, Kish B, Stern A, Sagiv P, Nyska M. Functional results after patellar fractures in elderly patients. Arch Gerontol Geriatr. 2003;37(1):93-8.

4. Matthews B, Hazratwala K, Rosa BS. Comminuted Patella Fracture in Elderly Patients: A Systematic Review and Case Report. Geriatr Orthop Surg Rehabil. 2017;8(3):135-44.

5. Kastelec M, Veselko M. Inferior patellar pole avulsion fractures: osteosynthesis compared with pole resection. J Bone Joint Surg Am. 2004;86(4):696-701.

6. Hoshino M, Tran C, Tiberi WV, Black J, Mary HL, Bonnie MG, et al. Complications Following TensionBand Fixation of Patellar Fractures with Cannulated Screws Compared with Kirschner Wires. J Bone Joint Surg. 2013;95:653-9.

7. Ilizarov GA. Trans osseous osteosynthesis. Berlin etc: Springer -Verlag; 2000: 429-432.

8. Maioochi AB. Treatment of Intra-articular fractures. In Operative Principles of Ilizarov by ASAMI group. Baltimore, Maryland, USA: Williams and Wilkins; 1991: 172.

9. Baruah R. Modified Ilizarov in difficult Fracture of the Patella. A case reports. J Orthopaedic Case Reports. 2016;6:26-8.

10. Wardak MI, Siawash AR, Hayda R. Fixation of patella fractures with a minimally invasive tensioned wire method: Compressive external fixation. J Trauma Acute Care Surg. 2012;72(5):1393-8.

11. Bari MM, Shetu NH, Rahman M, Munshi MH. Treatment of patella fractures by compressive external fixation. MOJ Orthop Rheumatol. 2015;2(6):70.

Cite this article as: Ponugoti G, Shah HM, Reddy S, Kolsur NC. Comminuted fracture of patella treated by primary Ilizarov external fixation: a case report. Int J Res Orthop 2020;6:865-7. 